\title{
Alternative Schools for Troublesome Secondary Students
}

\author{
Martin Gold and David W. Mann
}

Results of a field experiment indicate that a certain kind of secondary school program reduced the disruptive behavior and improved the scholastic performance of students who were about to be suspended or expelled from their conventional schools. The research indicates that the program was demonstrably effective only with those students who were not at the outset extremely depressed and anxious. The essential characteristics of the program are described. The findings document the social psychological processes by which the program achieved its goals. Implications are drawn for a typology of delinquency; causes of delinquent and disruptive behavior; stigmatization; the possibility of an educational program being effective without the direct involvement of disruptive students' families or friends; and for some recurring questions regarding the design of alternative educational programs.

Martin Gold

Professor of

Psychology, and

Program Director,

Institute for Social

Research, University

of Michigan.

David W. Mann,

Consulting

Psychologist,

Rohrer, Hibler, and

Replogle, Inc.,

Southfield,

Michigan.
The research summarized here is a longitudinal study of the effectiveness of certain alternative secondary schools in improving the behavior of delinquent and disruptive students. The three alternative schools studied were selected by theoretical criteria because this research was intended not only to assess the schools' effectiveness but also to test a theory which identifies scholastic experiences as a major source of provocation to delinquency.

Our theory made us especially interested in some innovative programs with which some school systems are addressing the problem of delinquent and disruptive behavior. These programs go under the generic name of alternative schools. One learns after only a brief scan of alternative schools that there are many different kinds of alternatives, with different philosophies, purposes, and methods. They serve a variety of kinds of students, not all of them by any means problematic. And, while some exist to address problems or deficiencies, others strive to open up new opportunities for their students. Alternative schools have been created for the gifted as well as the poor student, for the well-behaved as well as the disruptive. Some could be described as "permissive," others, as "strict"; some concentrate on basic scholastic skills while others pursue special talents and interests; and so on. About all that alternative schools have in common is that their programs are somehow different from the curriculum followed by the large majority of the community's students.

We were specifically interested in those alternative schools designed to serve students identified as behavior problems in their conventional 
schools. These problems include chronic truancy, disruptive behavior, and serious delinquency. Among the many kinds of alternative schools can be found a substantial proportion with this mission. Accurate figures are not available, but students of alternative education indicate that approximately a third of alternative programs are designed as responses to these problems (see Arnove, 1978). Within these limits, however, there is still a wide variety of approaches: disciplinarian; " back to basics"; detention; behavior modification; and others (Deal and Nolan, 1978).

Our immediate interest did not include just any alternative school designed for troublesome or troubled students. Our theory directed us only to programs that displayed certain characteristics which according to the theory should make these alternative schools effective in reducing disruptive and delinquent behavior. We identified schools of the requisite type and were fortunate in enlisting the participation of them and their school districts.

The alternative school programs made special efforts (1) to provide their students, who had had histories of scholastic failure, with experiences of success, largely through individualized instruction and evaluation; and (2) to provide social support from warm, accepting teachers. According to the theory, scholastic success and social support were hypothesized to raise the students' self-esteem and strengthen the social bonds that integrate students with their schools. Thus, the provocation to be delinquent would be reduced, the social constraints against delinquency would be strengthened, and consequently disruptive and delinquent behavior would decline.

\section{THEORETICAL FRAMEWORK}

The theory that guided this research assumes that the student role is central and critical for American adolescents. Therefore, failure in this role constitutes a substantial threat to adolescents' self-esteem. Derogated selfesteem is psychologically aversive and provokes efforts to counteract it. Delinquent behavior is one such defensive response that is particularly well-suited to this purpose. Delinquent behavior, especially disruptive behavior at school, can be an effective defense for several reasons. First, since a major provocation is failure at school, then disrupting school is a counterattack on the threatening institution. Second, assuming that delinquent and disruptive behavior is a self-aggrandizing performance, its worth is enhanced by the appreciative peer audience often available at school. Third, delinquent and disruptive behavior at school conveys a declaration of rebellion against the standards of success set by the schools.

\section{THE STUDENTS AND THE ALTERNATIVE PROGRAMS}

The students in the study were on the average quite heavily delinquent. Their self-reported delinquent behavior was markedly more frequent and serious than the national average found in the National Surveys of Youth 
(Gold and Reimer, 1975). The students also had histories of poor performance and disruptive behavior at school. About half of those who attended the alternative schools were sent there by school officials and the other half volunteered, although poor school grades and high levels of self-reported delinquent behavior were similar among the referrals and the volunteers.

The three alternative programs were operated by two public school systems in white, working- to middle-class suburban areas. The programs served 30-60 students at a time in buildings near the junior and senior high schools which the students would ordinarily have attended. The curricula and procedures were more informal than the conventional schools'; there were many fewer rules, and the administrators and teachers were more tolerant and flexible than faculty in conventional schools ordinarily are or can be. Teacher/student ratios were higher than is usually the case in secondary schools. Instances of disruptive behavior in the alternative schools were rare.

Two of the alternative programs, Alpha and Beta, featured independent study/learning contracts. The students in each also met daily as a group for one and a half to two hours for training in human relations and communication skills. The third program, Ace, offered a more conventional school curriculum and schedule, except that Ace was smaller, more individualized, more flexible, and more warm and personal than a conventional program.

\section{STUDY DESIGN}

Students attending the alternative schools were compared with students at the conventional schools from which they came. The comparison group consisted largely of students who were named by counselors and viceprincipals as students also appropriate for alternative school referral. (The original design called for random assignment of students to the alternative programs from a pool of referrals and volunteers. Agreements on randomization were made at a time when it was believed that the alternative schools would be as oversubscribed as they had been in previous years. But when the time came to make assignments, there was not in fact oversubscription, so all referrals and volunteers were enrolled in the alternative schools and comparison students were identified later.) The alternative and conventional students were interviewed once early in the school year, as alternative students entered their programs, again at the end of the school year, and a third time in the following fall.

Of the 240 students initially identified as suitable participants in the study, 100 were alternative school students and 140 were students in the comparison group who attended only the conventional school. We interviewed $83 \%$ of the alternative school students and $69 \%$ of the comparison group in the first wave. In the third wave, we interviewed $72 \%$ of the originally identified alternative students and $64 \%$ of the conventional students.

The alternative and conventional students were quite similar when the study began. There were about the same proportions of boys and girls in 
each group; the grade point averages of the students in the two groups were equally poor; personal adjustment, assessed by psychological indexes of self-esteem, anxiety, and depression was about the same in both groups; both groups had equally negative attitudes toward school generally and equally small commitment to the role of student; and their disruptive and delinquent behavior was at about the same high level, as indicated by the schools' records of disciplinary action and by the students' own reports of their behavior in school and in the community. The alternative students and the conventional comparison group also differed to a statistically significant degree in some respects: the alternative students were somewhat younger, they were more negative about their conventional school teachers, more pessimistic about their chances of succeeding at school, and felt more stigmatized as "bad kids."

\section{MEASUREMENT AND DATA ANALYSIS}

A key variable in this study is, of course, whether students attended an alternative school or not. (Many alternative school students took some conventional school courses concurrently.) But since we are also interested in the social psychological processes by which the alternative programs intended to improve the students' performance and behavior, we constructed measures of these mediating processes as well. One is an index of students' perceptions of the flexibility and faimess of their schools' policies and rules. Another is the students' assessment of their academic prospects-their beliefs in their chances of being successful students, together with their feelings of being stigmatized if they attended an alternative school. A third mediating variable is respondents' assessments of how well they were currently performing in the student role-including their most recent course grades, their reports of the effort they were devoting to schoolwork, and their satisfaction with their performance. Fourth, we measured students' global attitude toward school, including participation in school activities and relationships with teachers.

Finally among the mediating variables, we measured students' selfesteem at both conscious and unconscious levels. We wanted to test that portion of our theory of delinquent behavior that asserts that a primary function of delinquent behavior is to defend poor students from feelings of low-esteem. We hypothesized that, as a psychological defense, delinquent behavior raises adolescents' conscious self-esteem but not their unconscious self-esteem. The latter would remain low until experiences such as scholastic success make defensive delinquency unnecessary. Our own prior research (Gold \& Mann, 1973; Mann, 1981) had shown that the more delinquent adolescent boys gave evidence of high conscious and low unconscious self-esteem. Furthermore, Kaplan (1976) has demonstrated that youth with low conscious self-esteem will subsequently commit more delinquent acts than youth with higher self-esteem; and that conscious self-esteem will rise as a result.

Disruptive and delinquent behavior in school and in the community was 
measured by the confidential reports of the students themselves, a widely used technique that has proved to be more sensitive and valid than official school, police, and court records.

All of these variables were measured among both alternative and conventional school students. Measures of change over the course of the study were also created, using a procedure-regression analysis-that corrects for unequal baseline levels.

Our basic strategy was to compare students who had had alternative school experience with those who had had none at each of the three time periods and with respect to changes over time. Comparisons were made of the two groups each taken as a whole and for each of the three programs. We determined whether alternative school experience made a difference in the mediating processes and in delinquent and disruptive behavior at the third time period, by which time most of the alternative school students had returned to the conventional schools. We also explored whether the alternative schools affected different kinds of students differently.

\section{FINDINGS}

The delinquent and disruptive behavior of both the alternative and conventional school students declined over the course of the study, probably reflecting in part a combination of statistical artifact ("regression to the mean") and actual improvement accompanying maturation. However, almost all of the social psychological processes that were hypothesized to make a difference in the misbehavior of youth indeed predicted to significant improvement. The alternative schools were more effective in putting these processes in motion.

We found that the effectiveness of the alternative school programs differed between the kinds of students in their classes. The alternative schools made a significant difference in the behavior of their more buoyant students, but they had a negligible effect on the more beset students.

The "beset"' students in this study were identified as those alternative and conventional students who exhibited relatively high levels of anxiety and depression during our first interview with them. They reported to us more than the average frequency of somatic symptoms of anxiety such as headaches and upset stomachs; they said they felt tense and nervous; they said that they more often "feel depressed." The beset students were those who scored in the top third of a scale composed of these indicators. We called the other two-thirds of the students "buoyant." The alternative and conventional school groups in this study each had about the same proportion of beset students. Beset students tended to be somewhat more delinquent than the buoyant students. They resemble the unsocialized "neurotic" type of delinquent that Hewitt and Jenkins (1946) identified from clinical records.

The beset alternative students did not respond as positively to the programs as the buoyant students did. Figure 1 presents the processes by which the alternative schools had a significantly more positive effect on the 


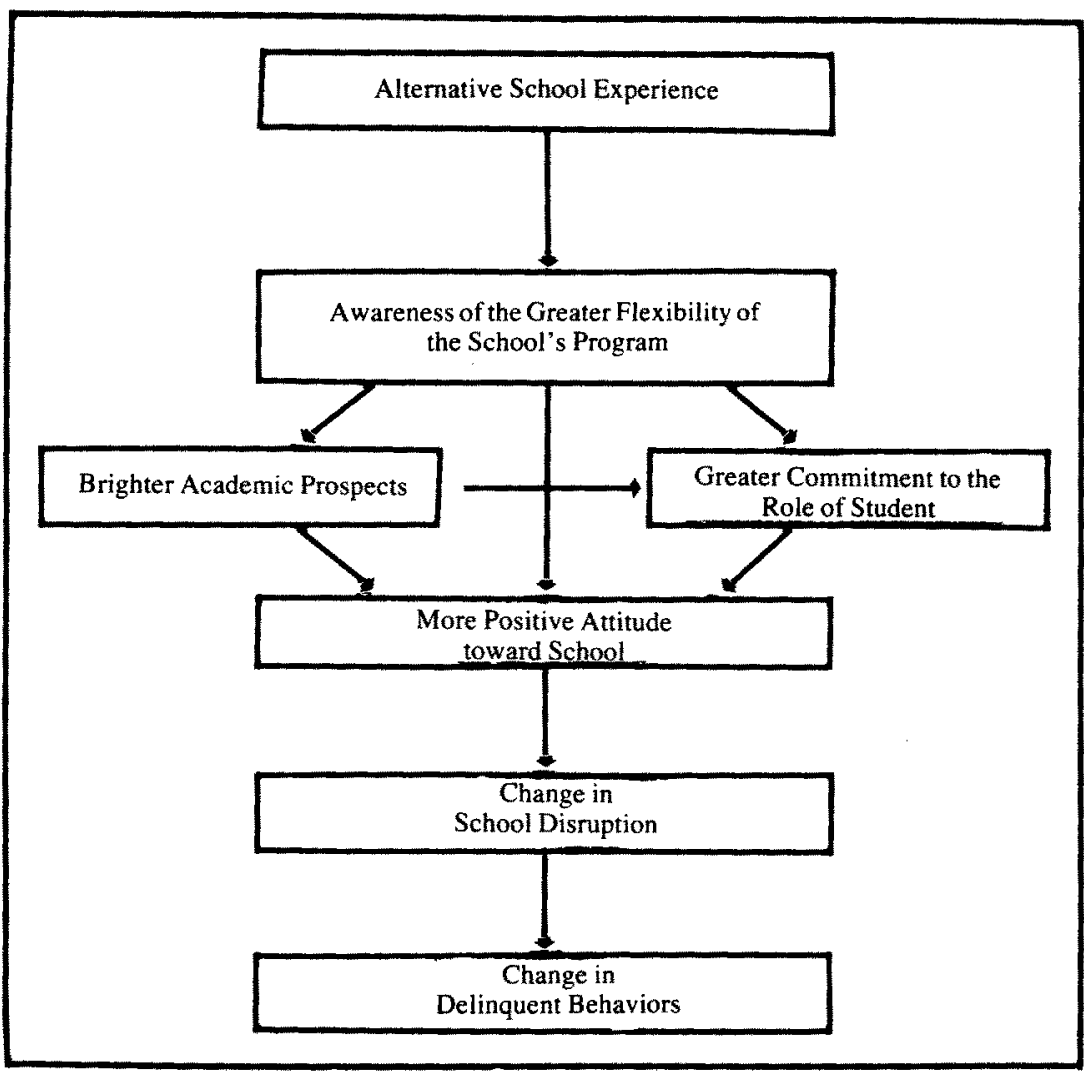

Fig. 1. Model of the social psychological process of change.

disruptive behavior of their buoyant students even after these students returned to the conventional schools. At critical points in these processes, the beset students responded differently.

Both buoyant and beset alternative students reported that their schools were more flexible and their rules more fair compared with the conventional students' descriptions of their schools. Clearly the two kinds of programs were perceived differently by their students. All students who rated their school as more flexible and fair tended to believe their own academic prospects were better than other students did. But the effect of greater flexibility in the alternative programs persisted only among their buoyant students after they returned to the conventional schools. By the third interview, the beset former alternative students were no more optimistic than the beset conventional students. Similarly, the perception of the flexibility of school rules was related to our respondents' commitment to the role of student. Since the alternative schools were seen as being more flexibile, they fostered greater commitment to the student role, but only 
among the alternative schools' buoyant students, who then remained more committed through the third interview. The beset alternative students as a group never exceeded their conventional counterparts in commitment to studenthood, despite their recognition of the alternative schools' greater flexibility.

In general, brighter academic prospects and greater commitment to being students were reflected in better global attitudes toward school among alternative and conventional students. And again, since the alternative school students became more optimistic and committed, their attitudes toward school were better. This remained true of the buoyant alternative students even after they returned to the conventional schools, but not of the beset students. Improved attitudes toward school were related to a greater decline in delinquent and disruptive behavior in school. Consequently, by the third interview, the buoyant former alternative students were behaving markedly better in school than their conventional counterparts according to students' own reports of their behavior and to ratings by their teachers. They were also earning higher grades. This was not true of the beset former alternative students.

Declining misbehavior in school was related to declining delinquency in the community. But, while this relationship was strong, it was of course not perfect. Neither the buoyant nor the beset former alternative students reported that they were less delinquent at the third interview than the conventional students did.

We can draw only highly tentative conclusions from comparing the three alternative programs because the numbers of students in any one program is small. Insofar as these comparisons can be trusted, it seems that the Alpha program had the most marked effects-positive and negative-on its students' grades and disruptive behavior in school. Alpha's buoyant students seemed most improved at the third interview, and its beset students appeared to deteriorate most relative to their respective comparison groups. This impression of Alpha's effectiveness is reinforced by the fact that the separate components of the change process (diagrammed in Fig. 1) seem more tightly linked at Alpha than at Beta or Ace. Alpha's relative success seems attributable to its greater effectiveness in increasing its buoyant students' commitment to the role of student. Greater commitment persisted more reliably into the conventional school year than positive global attitudes toward school, on which the effects of Beta and Ace depended more heavily. At the same time, Alpha's beset students did not become more committed to the student role, just as Beta's and Ace's beset students did not. But since Alpha's effectiveness depended so heavily on commitment, its beset students fared worst. Alpha probably achieved the greater commitment of its buoyant students through the greater emotional intensity of its program which, of the three programs we observed, most closely resembled group therapy. But the intensity of introspection encouraged by Alpha's method may have worked to the disadvantage of the beset students who were at the outset quite anxious and depressed.

One of the potentially negative aspects of an alternative school experience is stigmatization. Youth may be made to feel that they are different in a 
derogatory sense by having been sent to a special school for " bad kids." A substantial number of administrators, teachers, and students did hold negative opinions about the alternative programs and the young people who went there. Many of the alternative students were aware of these attitudes and shared them at first. But by our third interview with them, the students who had had an alternative school experience were almost invariably positive about the school and their classmates. So few students at that point expressed feelings of stigmatization that it is impossible with our data to determine whether stigma hindered the alternative schools' efforts. We conclude that alternative schools can be effective even though they may be negatively regarded by the educators and students in the associated conventional schools.

It should be noted that the alternative schools were as much if not more successful with their more highly delinquent students. The positive effects of the alternative schools on their buoyant students was greater with those who had been more disruptive and delinquent when they first entered the programs. But the alternative schools had negligible effects on beset students regardless of their history of misbehavior. Clearly then the alternative schools' ineffectiveness with their beset students was not due to the beset students' higher level of delinquency.

The effects of the alternative schools were not mediated by nor conditioned by the level of delinquency of their students' friends. The schools had no discernible effect on changing their students' friends or the degree of their friends' delinquency. If anything, the alternative schools were more successful with those buoyant students who reported having more delinquent friends. We believe that this is actually a reflection of the schools being more effective with students who were more delinquent themselves (and who chose to hang around with more delinquent friends).

Nor did the effects of the alternative schools depend upon changing their students' relationships with their parents. None of our data indicate that the social psychological processes by which the alternative schools effected change among their buoyant students involved students' parents. While improving relationships between students and parents would probably improve most adolescents' behavior, it is not a necessary condition for the effectiveness of school programs.

Our theory of a particular kind of alternative school as a means for reducing disruptive and delinquent behavior posits that youngsters' selfesteem is a key variable. We found a general decline in students' conscious self-esteem over the course of this study, about equal among alternative and conventional students. Nevertheless, improvement in the behavior and performance of the buoyant alternative students occurred without discernible change in their unconscious self-esteem and in the face of a decline in their conscious self-esteem. Self-esteem proved not so crucial to the processes of change as we had expected it to be. In this respect, the theoretical model was not confirmed, a surprising finding in the light of previous research. 


\section{DISCUSSION}

The assertion that poor scholastic experiences are significant causes of delinquent and disruptive behavior, particularly at school, received substantial support in this study. As certain youngsters' assessments of their schools and of themselves as students became more positive, their scholastic performance and their behavior improved.

Given these findings, the question arises of whether school-based programs might better screen out manifestly depressed and anxious students because the programs are less likely to help them. Such screening would be advisable if anxiety and depression could be diagnosed accurately, but this is difficult under the best of circumstances and few school systems have the resources to do this well. It seems wiser to us, therefore, to employ alternative school programs in the diagnostic process: if certain students' behavior does not improve despite their greater satisfaction with the alternative program, then a search for other points of intervention might be made. It may be wise to permit beset students to remain in alternative schools for a longer period, perhaps even to graduate from them.

We also note that the positive effects of the alternative schools were narrow, bearing most clearly on students' behavior at school and not reliably on delinquent behavior in the community. Perhaps the effects were narrow because the mediating changes were limited to school-related optimism and commitment. It is possible that unless or until youngsters" scholastic experiences enhance self-esteem globally, they will not have a global effect on their misbehavior. We have assumed that performance at school is highly salient to adolescents in western culture, and that being good at it would enhance self-esteem globally. Perhaps we have overestimated the breadth of its impact.

On the other hand, it may be that the timing of our final interview with the students, one term after they had returned to the conventional schools, did not allow sufficiently for youngsters' self-esteem to change. The students may not yet have been altogether convinced of their ability to make it through school, despite their greater optimism. If this is the case, then we would expect that a follow-up study of these students will demonstrate the importance of self-esteem as a mediator for a wider and enduring change in their behavior.

There is one ominous sign in our data on self-esteem: the conscious self-esteem of the buoyant students and of the beset alternative students had declined significantly from our first to our third interviews with them. If it is true that low conscious self-esteem is provocative to disruptive and delinquent behavior, as Kaplan has found (1980), then we can expect a resurgence of misbehavior in the future. Or, if for some reason, delinquency proves to be an inadequate defense, then we can expect increased anxiety and depression. A follow-up study will check these expectations.

Our findings relating to students' families and friends also have theoretical and practical implications. Change in the buoyant students' behavior and scholastic performance, we found, did not depend upon improved relationships with their parents or diminished delinquency among 
their friends. These data speak to the salience of scholastic experiences, which seem to have marked influence in their own right, whether as sources of provocation and/or of social control. It is likely that the salience of schooling is pervasive throughout western culture, but it is plausible that there are subcultural differences. School-based programs may not be so effective in these subcultures, independent of other influences like families and friends. For example, we are mindful that almost all the students in our study were white suburbanites. Would alternative programs like the ones we observed work among black residents of the inner city? We think so, but of course, they would have to be tried. We think so because there are sufficient data in hand to indicate that schooling is certainly no less salient for black adolescents and their parents and perhaps even more salient (Coleman et al., 1972; Tucker et al., 1980).

We are not surprised that the alternative schools had independent positive effects on the behavior of buoyant students, at least at school. After all, the thrust of adolescence in our culture is to become more autonomous from parents and more serious about schoolwork. While most adolescents are still closely bound in many ways to their parents the familial ties of most heavily delinquent youngsters are weaker. Our data reflect this: the students' attitudes toward school were more closely related to their delinquency than were their relationships with their parents. A possible exception to this generalization is the beset students' relationships with their mothers, which seemed more closely related to their behavior. This is consistent with our observation that the alternative programs were not effective with beset students because school was not the main source of their problems.

At the same time that adolescents are becoming more independent of parental influence, they are becoming more involved with their friends and peers. One might expect therefore that the delinquent tendencies of students' friends would be important influences on the students' behavior. But having delinquent friends is more likely a consequence of needing support for one's own delinquent behavior than a cause of that behavior. Buoyant students' disruptive and delinquent behavior at school declined even while they were reporting no change in their friends' behavior. We expect that students whose improved performance and behavior persist will however eventually begin to select less delinquent friends.

The practical significance of our findings relating to students ' parents and friends is that educators need not depend upon reaching disruptive students' parents or changing disruptive students' friendship patterns in order to reduce disruption in their schools. Alternative programs of the kind we have observed can be independently effective with their more buoyant students. But it may be important that someone intervene with the parents of the beset students who do not respond positively to an alternative school.

Of particular practical significance is our finding that students' perceptions of their alternative school being flexible is critical to positive change. Many of the concrete options for designing alternative programs may be selected on the basis of the general principle of enhancing flexibility.

"Flexibility"' in this instance means taking into account the individual 
students' needs, fears, abilities, and moods in conducting the daily business of education. We regard flexibility as another term for interpersonality or the absence of rigid role regulation of social interactions. It is manifested in part by a relative suspension of the conventional rules governing how teachers and students behave toward one another. Another manifestation is the alteration of planned activities to accommodate to the mood of the class as a whole.

For example, one option for an alternative program is to house it in a building separate from the conventional high school that the students would ordinarily attend. Our observation of the schools in this study suggest to us that being in separate buildings contributed a great deal to the flexibility of the programs. The more casual comings and goings of alternative students, the occasionally higher noise level, the regular availability of coffee and a place to smoke, and other deliberate informalities that created the ambience of the alternative programs probably could not have been tolerated in the midst of a conventional comprehensive secondary school. At the same time, the potential danger of stigmatization by the implication of isolation and quarantine did not materialize, according to our data. The proximity of the separate facilities to the conventional junior and senior high schools of course facilitated the attendance of students in selected classes and students' transitions back to the conventional schools.

For another example: There seems to be a growing consensus among educators, despite the lack of any reliable data, that the principal is a major determinant of the level of disruptiveness in a school. Furthermore, the consensus seems to be that firm discipline and organization are the hallmarks of effective principals. Our data on the importance of perceived flexibility suggest, on the other hand, that disruptive students may not respond so well to the projection of such a principal's style onto the school program if discipline and organization mean inflexibility. Certain students may be disruptive because they have chronic problems dealing with authority and because their frequent experiences of failure in school make any universal standards of behavior and performance threatening to them. If the principal is indeed a key element in minimizing school disruption, this study suggests that it is because his or her administration permits and encourages the staff to develop more interpersonal relationships even with the most disruptive students and to accommodate to their individuality.

We recognize that the desirable flexibility of alternative schools contains an element of unfairness. This unfairness, we think, is a major source of opposition to alternative schools among faculty and staff of conventional schools. Conventional school teachers quite rightly feel strongly their obligation to treat their students evenhandedly, which includes holding them equally to scholastic standards. But it is apparent that this principle is not followed in the kind of alternative school we observed in this study. So these alternative schools are open to the charge that their students earn scholastic credits with less effort, that they receive passing grades for below-standard work, and that they are privileged to break ordinary school rules. And this, it is pointed out, as a consequence of behaving intolerably badly! But we need to remember that the intolerable behavior was generated 
under conditions of fixed standards for performance and behavior, applied evenhandedly. These are conditions with which for whatever reasons, disruptive students are developmentally unable to deal. It is arguable, nevertheless, that adolescents need to learn to deal with these conditions, for schools reflect the society they serve. And it is also arguable that, according to our data, temporary suspension of these conditions is efficacious for that learning to occur, at least by students who are not extremely anxious and depressed. Tailoring the level and pace of learning to the individual student's abilities and interests, and fostering interpersonal relations between teachers and students contradict our conventional sense of fairness. Psychologically, however, the conditions of the alternative schools seemed to their students more fair than those of the conventional schools.

Producing statistically significant differences between "treatments" is only a tool of action-research, not its ultimate aim. The present findings also offer guidance to conventional secondary school administrators that will help to improve the educational process. While the constraints under which conventional junior and senior high schools operate-large size, low teacher/student ratios, pressures to evaluate students impersonally, etc.make it impossible for them to adopt wholly the procedures of effective alternative schools, they may be able to alter their programs to a degree and on occasion to accommodate the needs of those students who are showing signs of failure and the negative behaviors consequent to failure so that many of them would not need to be sent to an alternative school. It appears that there is much to be gained generally from educational practices that impress students with their fairness and flexibility; from curricula whose level and pace meet students at their current level of academic adjustment and achievement; and from teaching styles that convey a sense of personal caring and support.

\section{REFERENCES}

Arnove, R. Alternative Schools for Disruptive Youth. Bloomington: Indiana University School of Education, 1978.

Coleman, J. W., Campbell, E. G., Hobson, C. J., McPartland, J., Mood, A. M., Weinfeld, F. D. and York, R. L. The locus of control and academic performance among racial groups. In Guterman, S. S. (Ed.), Black Psychology. Berkeley, Cal.: The Glendessary Press, 1972.

Deal, T. E. and Nolan, R. R. Alternative Schools. Chicago: Nelson-Hall, 1978.

Gold, M. and Mann, D. Delinquency as defense. American Journal of Orthopsychiatry, 1972, 42, 463-479.

Gold, $M$. and Reimer, D. Changing patterns of delinquent behavior among Americans 13 through 16 years old: 1967-1972. Crime and Delinquency Literature, 1975, 7, 483-517.

Hewitt, L. D. and Jenkins, R. L. Fundamental Patterns of Maladjustment. Springfield: The State of Illinois, 1946.

Kaplan, H. B. Self attitudes and deviant response. Social Forces, 1976, 54, 788-801.

Mann, D. W. Age and differential predictability of delinquent behavior. Social Forces, 1981, 60 , $97-113$.

Tucker, M. B., Jackson, J. S. and Jennings, P. M. Occupational expectations and drop-out propensity in urban black high school students. In A. W. Boykin, et al. (Eds.), Research Directions of Black Psychologists. New York: Russell Sage Foundation, 1980. 